Оригинальные статьи / Original articles

https://doi.org/10.18619/2072-9146-2021-1-58-62 УДК 635.54:631.52

О.М. Вьютнова, И.В. Смирнова, Е.А. Евсеева, Т.Ю. Полянина, Н.А. Ратникова, И.А. Новикова

Ростовская овощная опытная станция по цикорию - филиал ФГБНУ ФНЦО 152130, Россия, Ярославская область, Ростовский район, с.Деревни rossc2010@yandex.ru

Конфликт интересов: авторы заявляют об отсутствии конфликта интересов.

Вклад авторов: Все авторы в равной доле участвовали в написании статьи.

Для цитирования: Вьютнова О.М., Смирнова И.В., Евсеева Е.А., Полянина Т.Ю., Ратникова Н.А., Новикова И.А. Подбор пар для межсортового скрещивания цикория корневого. Овощи России. 2021;(1):58-62. https://doi.org/10.18619/2072-9146-2021-158-62

Поступила в редакцию: 27.08.2020

Принята к печати: 15.12 .2020

Опубликована: 25.02.2021

Olga M. Vyutnova, Irina V. Smirnova, Elena A. Evseeva, Tatyana Yu. Polyanina, Natalya A. Ratnikova, Irina A. Novikova

Rostov Vegetable experimental station on chicory - Branch of the FSBSI FSVC Derevni v., Rostov district, Yaroslavl region, Russia, 152130

rossc2010@yandex.ru

Conflict of interest: the authors declare no conflict of interest.

Authors' Contribution: All authors contributed equally to the writing of the article.

For citations: Vyutnova O.M., Smirnova I.V. Evseeva E.A., Polyanina T.Yu., Ratnikova N.A. Novikova I.A. Selection of pairs for intervarietal crossing of root chicory. Vegetable crops of Russia. 2021;(1):58-62. (In Russ.) https://doi.org/10.18619/2072-9146-2021-1$58-62$
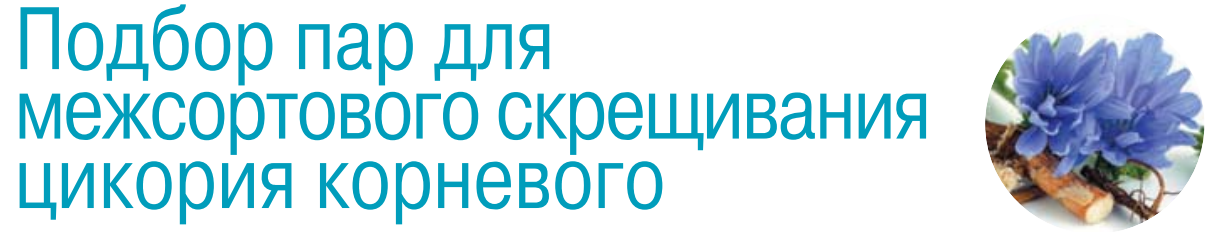

Резюме

Актуальность. Современное сельскохозяйственное производство требует создания сортов, сочетающих высокую продуктивность, качество, адаптивность. Учитывая тенденции развития современного сельского хозяйства к многоукладности, необходимо совершенствовать и расширять сортимент, способствуя удовлетворению запросов как крупных, так и мелких производителей сельскохозяйственной продукции. Из-за нехватки материальных и людских ресурсов в сельскохозяйственной отрасли ощущается явная потребность в сортах и гибридах, приспособленных к промышленным технологиям возделывания и хранения. Существующие районированные сорта корневого цикория имеют корнеплод длиной 40 и более см, а почвы района цикоросеяния в основном тяжёлые по механическому составу, где применение выкапывающих устройств на такую глубину невозможно. Производству необходимы сорта с коротким корнеплодом, у которого основная масса сосредоточена в верхней части.

Материал и методика. Цель работы -среди многообразия сортообразцов цикория корневого разного эколого-географического происхождения выделить селекционно-ценные генотипы в почвенно-климатических условиях Нечернозёмной зоны РФ для использования их в создании исходного материала селекции методом межсортовых скрещиваний. Исследования проводили в Нечернозёмной зоне РФ в Ростовском районе Ярославской области на базе Ростовской опытной станции по цикорию в 2015-2019 годах.

Результаты. При создании исходного материала для селекции цикория корневого методом межсортовых скрещиваний одним из родителей следует выбирать местные внутризональные сорта, приспособленные к почвенно-климатическим условиям зоны цикоросеяния (Ярославский, Гаврилов-Ямский), а вторым - внезональные сорта, обладающие хозяйственно ценными качествами (короткий корнеплод, высокие урожайность и химико-технологические показатели, устойчивость к корневым гнилям) и являющиеся донорами этих признаков (Харпачи, Sleszka, BilogorkaOS-2, BilogorkaOS-3, Rexor, Wixor, Luxor).

Ключевые слова: цикорий корневой; сортообразец; селекция; хозяйственно ценные признаки; селекционно ценные генотипы

\section{Selection of pairs for intervarietal crossing of root chicory}

\section{Abstract}

Relevance. Modern agricultural production requires the creation of varieties that combine high productivity, quality, and adaptability. Taking into account the development trends of modern agriculture towards multiplicity, it is necessary to improve and expand the assortment, helping to meet the needs of both large and small producers of agricultural products. Due to the lack of material and human resources in the agricultural sector, there is a clear need for varieties and hybrids adapted to industrial cultivation and storage technologies. Existing zoned varieties of root chicory have a root crop length of $40 \mathrm{~cm}$ or more, and the soils of the area of cycoroseeding are mainly heavy in mechanical composition, where the use of digging devices to such a depth is impossible. Production requires varieties with a short root crop, which has the main mass concentrated in the upper part.

Methods. The purpose of this work is to identify valuable genotypes in the soil and climate conditions of the non-Chernozem zone of the Russian Federation among the variety of varieties of chicory root of different ecological and geographical origin for use in the creation of the source material of selection by inter-port crosses.

Results. When creating the source material for the selection of root chicory by the method of intervarietal crosses, one of the parents should choose local intrazonal varieties adapted to the soil and climatic conditions of the zone (Yaroslavsky, Gavrilov-Yamsky), and the second - off-zonal varieties with economically valuable qualities (short root crop, high yields and chemical-technological indicators, resistance to root rot) and donors of these traits (Kharpachi, Sleszka, BilogorkaOS-2, BilogorkaOS-3, Rexor, Wixor, Luxor).

Keywords: root chicory; variety type; selection; economically valuable traits; breeding valuable genotypes 


\section{Введение}

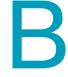
решении самых сложных задач современного растениеводства, связанных, в первую очередь, с устойчивым ростом его продуктивности, ресурсоэкономичности и природоохранности, создание и широкое использование новых сортов и гибридов растений занимает центральное место. Успех и срок создания новых сортов во многом зависят от правильного подбора исходного материала, представляющего начальный этап селекционной работы. Особенно это относится к видам растений, которые имеют двухлетний цикл развития [1].

Особо ценным материалом для селекции являются местные внутризональные сорта, так как они в большей степени акклиматизированы и приспособлены к почвенно-климатическим условиям района, области, зоны.

Внезональные сорта - это сорта, завезённые из других районов или стран, обладающие хозяйственно ценными признаками [2].

Селекция любого вида растений включает два этапа: создание резерва генотипической изменчивости и отбор нужных генотипов. На первом этапе селекции для целенаправленного поиска исходного материала необходимо создание модели сорта, учитывающей реализацию его генетического потенциала в условиях того региона, для которого предназначен сорт. Модель сорта определяет и способ его получения и будущие условия культивирования.

Составной частью всех методов селекции является отбор, который подразделяется на массовый и индивидуальный. При позитивном массовом отборе, как правило, отбирают от 5 до 15\% исходных растений. Индивидуальный отбор, эффективность которого была продемонстрирована в 50-х годах XIX столетия в работах Л. Вильморена, остаётся широко используемым методом, особенно у новых сельскохозяйственных культур. В отличие от самоопыляющихся видов, индивидуальный отбор у перекрёстноопыляющихся растений проводят на основе контролируемого опыления [3].

А.А. Жученко (1980) была предложена и обоснована концепция селекционного процесса. Ниже приводятся её основные моменты.

«Всё многообразие методов селекции можно дифференцировать на три большие группы:

1) управление доступной отбору генотипической изменчивостью (мутационная и комбинационная);

2) распознавание искомого генотипа за «фасадом» фенотипа (индивидуальный отбор с оценкой по потомству, массовый, ступенчатый отборы, подбор фонов, применение инструментальных оценок признаков);

3) фиксация приемлемых для использования генотипов и агрофитоценозов (гибридная и гетерозисная селекция, синтетические и многолинейные сорта, смешанные посевы). Селекция, ставящая своей целью сочетать количественные или качественные признаки двух и более родителей, называется комбинационной.»

По мнению А.А. Жученко, особый интерес представляет комбинационная селекция, ориентирующаяся на получение генотипов, превосходящих по какому-то количественному или качественному признаку все исходные формы или сочетающих несколько признаков лучших по их проявлению родительских линий, которую принято называть трансгрессивной.
Основным методом создания селекционных популяций является гибридизация. Успех создания гибридной популяции зависит от правильности подбора родительских пар. Этому должны предшествовать оценка генетической коллекции носителей адаптивных признаков (отзывчивость к регулируемым факторам среды) и устойчивость к нерегулируемым факторам среды (недостаток или избыток тепла, влаги и др.), для чего необходима широкая географическая сеть испытаний в контрастных и типичных для основных зон сельскохозяйственного производства условиях среды [3].

Выделяют следующие основные методы подбора родительских компонентов селекции растений:

1. Оценка комбинационной способности родителей. При этом используют диаллельные, топкроссные и поликроссные виды скрещиваний.

2. Идентификация перспективных гибридных комбинаций с помощью генетического анализа ранних поколений ( $F_{1}, F_{2}, P_{1}, P_{2}$, беккроссов).

3. Планирование скрещиваний на основе данных изучения сортов и линий по степени их дивергентности с последующим скрещиванием генетически отдалённых форм [4].

Наиболее полную генетическую информацию о свойствах и признаках исходного материала можно получить, используя систему диаллельных скрещиваний.

Современное сельскохозяйственное производство требует создания сортов, сочетающих высокую продуктивность, качество и адаптивность. Учитывая тенденции развития современного сельского хозяйства к многоукладности, необходимо совершенствовать и расширять сортимент, способствуя удовлетворению запросов как крупных, так и мелких производителей сельскохозяйственной продукции. Из-за нехватки материальных и человеческих ресурсов в сельскохозяйственной отрасли ощущается явная потребность в сортах и гибридах, приспособленных к промышленным технологиям возделывания и хранения. Существующие районированные сорта корневого цикория имеют корнеплод длиной 40 и более см, а почвы района цикоросеяния в основном тяжёлые по механическому составу, где применение выкапывающих устройств на такую глубину невозможно. Производству необходимы сорта с коротким корнеплодом, у которого основная масса сосредоточена в верхней части.

Цель работы - среди многообразия сортообразцов цикория корневого разного эколого-географического происхождения выделить селекционно-ценные генотипы в почвенно-климатических условиях Нечернозёмной зоны РФ для использования их в качестве родительских компонентов при создании нового исходного материала методом межсортовой гибридизации.

Материал и методика проведения исследований Исследования проводили в Нечернозёмной зоне РФ в Ростовском районе Ярославской области на базе Ростовской опытной станции по цикорию в 2015-2019 годах в полевых условиях, сопровождающихся сопутствующими наблюдениями и анализами.

При проведении исследований руководствовались следующими рекомендациями и методическими указаниями: «Методика полевого опыта» [5]; «Методика опытного дела в овощеводстве и бахчеводстве» [6], 
Таблица 1. Исходный материал цикория корневого

Table 1. Initial material for the selection of root chicory

\begin{tabular}{|c|c|c|c|}
\hline $\begin{array}{l}\text { № } \\
\text { п/п }\end{array}$ & $\begin{array}{c}\text { № } \\
\text { каталога ВИР }\end{array}$ & $\begin{array}{c}\text { Название } \\
\text { образца }\end{array}$ & Происхождение \\
\hline 1 & K-6 & Sleszka & Чехия \\
\hline 2 & Торговая марка & Spicak & Чехия \\
\hline 3 & K -10 & BilogorkaOS-3 & Югославия \\
\hline 4 & ВРК -27 & Bilogorka OS-2 & Югославия \\
\hline 5 & ВРК -23 & Подлуга Куявска & Польша \\
\hline 6 & BPK - 22 & Поляновицка & Польша \\
\hline 7 & Торговая марка & Berguce & Франция \\
\hline 8 & ВРК -24 & TidWog & Франция \\
\hline 9 & Торговая марка & Cassel & Франция \\
\hline 10 & Торговая марка & Orchies & Франция \\
\hline 11 & $K-11$ & AlbinoRVP & Бельгия \\
\hline 12 & BPK -20 & Novipa & Бельгия \\
\hline 13 & ВРК -26 & Rexor & Голландия \\
\hline 14 & ВРК -28 & Luxor & Голландия \\
\hline 15 & ВРК -29 & Wixor & Голландия \\
\hline 16 & Торговая марка & Wonfblane & Голландия \\
\hline 17 & K -5 & LardRooted & Канада \\
\hline 18 & K -8 & Харпачи & Венгрия \\
\hline 19 & BPK -21 & Гаврилов-Ямский & Россия \\
\hline 20 & ВPК -20 & Ярославский & Россия \\
\hline
\end{tabular}

«Методические указания по изучению и поддержанию мировой коллекции корнеплодов ВИР» [7].

Материалом исследований служили 20 сортообразцов цикория корневого отечественной и зарубежной селекции, полученные из ВИР им. Н.И. Вавилова и стран - оригинаторов сортов (табл. 1).

На участках, где закладывали опыты, проводили следующие агротехнические мероприятия: весновспашка по зяби, предпосевная культивация фрезерным культиватором КФН - 2,8, нарезка гребней, в течение вегетации три междурядные обработки культиватором КФЛ 4,2, две ручные прополки с прореживанием. Посев и уборку цикория корневого проводили вручную.

Размеры и схемы размещения делянок устанавливали, согласно требованиям ОСТ 4671-78 «Делянки и схемы посева в селекции, сортоиспытании и первичном семеноводстве овощных культур. Параметры» [8].

Опыты закладывали на гребнях с междурядьями 0,7 см, учётная площадь делянки при испытании сортообразцов составила 2,8 м2 в двукратной повторности.

В процессе проведения учетов и наблюдений оценку коллекционных образцов вели по морфобиологи- ческим параметрам листовой розетки и корнеплода, показателям урожайности, товарности, продолжительности вегетационного периода и их фенофаз, химическому составу корнеплодов. Морфологическое описание растений, учёт фенофаз проводили согласно «Руководству по апробации овощных культур и кормовых корнеплодов» (1982). Учёт урожая проводили в фазе технической спелости корнеплодов. Учитывали товарные, а в нетоварной части недоразвитые, больные, уродливые и цветушные растения по РСТу РСФСР 309-77 [10]. Проводили замеры длины и диаметра корнеплода для определения индекса формы.

\section{Результаты исследований}

По продолжительности вегетационного периода можно выделить раннеспелые (вегетационный период составляет менее 125 суток), среднеспелые (125-139 суток) и позднеспелые сорта цикория корневого (более 139 суток). Группы образцов корневого цикория разного эколого-географического происхождения по срокам спелости представлены в таблице 2.

Таблица 2. Группировка сортообразцов корневого цикория по срокам созревания (в среднем за 2015-2019 годы)

Table 2. Grouping of root chicory cultivars by ripening dates (2015-2019)

Группа спелости

Раннеспелые (продолжительность

вегетационного периода менее 125 суток)

Среднеспелые (продолжительность

вегетационного периода 125-139 суток)

Позднеспелые (продолжительность вегетационного периода более 139 суток)
Сортообразец

Харпачи, Slesazka, Rexor, Luxor, Wixor

Подлуга Куявска, Поляновицка, Ярославский, BilogorkaOS-2, Bilogorka OS-3, Spicak, TidWog, Novipa, LardRooted

Гаврилов-Ямский, Berguce, Cassel, Albino RVP, Wonf blan 
Таблица 3. Группы сортообразцов корневого цикория по форме корнеплода Table 3. Groups of root chicory varieties according to the shape of the root crop

1 (с короткими коническими корнеплодами)

Иф менее 5,0

2 (с длинными цилиндрическими и полудлинными корнеплодами) Иф 5,0 - 7,0

3 (с веретеновидными удлинёнными корнеплодами) Иф более 7,0

Наиболее многочисленной оказалась группа среднеспелых сортов, которая включает 9 образцов из 20. Особый же интерес для нашей селекционной работы имеют более раннеспелые сорта, так как в условиях НЧЗ РФ к календарным срокам уборки позднеспелые сорта не достигают биологической спелости, их корнеплоды не набирают максимальную массу, отчего фактическая урожайность не достигает потенциально возможной величины. Кроме того, не достигшие биологической спелости, но уже убранные корнеплоды, не накопив достаточного количества питательных веществ, хуже хранятся. К ним относятся Sleszka, Rexor, Luxor, Wixor и Харпачи, длина вегетационного периода которых не превышает 125 суток. Эта группа сортов является наиболее ценной при селекции на скороспелость.

Сорта корневого цикория отличаются друг от друга, прежде всего, величиной и формой корнеплода. От размеров корнеплода зависит его индекс формы (Иф), который определяется отношением длины к диаметру. Для селекционной работы с цикорием корневым важно, какую форму имеет корнеплод. Предпочтительно, чтобы его основная масса была сосредоточена в верхней части. В этом случае механизировано будет убираться урожай почти без потерь. К таким сортам относятся Харпачи, Sleszka, Wixor, Luxor, Rexor.

Непригодными для выкапывания серийно выпускаемыми для этой операции машинами в зоне цикоросеяния являются длиннокорневые сорта, уборка которых
Харпачи, Sleszka, Rexor, Luxor, Wixor

Ярославский, Гаврилов-Ямский, Подлуга Куявска, Поляновицка, Bilogorka OS-2, Bilogorka OS-3, Berguce, Cassel, Orchies, Lard Rooted

Spicak, Tid Wog, Albino RVP, Novipa, Wonf blane

на тяжёлых по механическому составу почвах НЧЗ РФ невозможна без больших потерь урожая.

Все сортообразцы отечественной и зарубежной селекции по форме корнеплода (в среднем за годы испытаний) были распределены на 3 группы: первая - с конической короткой формой корнеплода, вторая - с цилиндрической и третья - с веретеновидной. У первой индекс формы корнеплода $<5,0$, у второй - от 5,0 до 7,0, у третьей - более 7,0 (табл. 3).

Наиболее многочисленно представлена вторая группа - 10 сортообразцов из 20. Особый интерес для нашей селекционной работы представляют сортообразцы первой группы, так как они благодаря своему короткому корнеплоду пригодны для механизированной уборки серийно выпускаемыми машинами.

Такими образом, выделены пять сортообразцов, которые и были включены нами в селекционную работу в качестве доноров признака «короткая коническая форма корнеплода» (Харпачи, Sleszka, Rexor, Luxor, Wixor) для создания исходного материала для селекции цикория корневого, пригодного к механизированной технологии.

Одним из самых важных показателей для всех сельскохозяйственных культур является урожайность. Причём важное значение имеют также и его товарные качества, выход товарной продукции с единицы площади. И для корневого цикория общая урожайность и товарность являются важнейшими показателями (табл. 4)

Таблица 4. Урожайные и товарные качества сортообразцов корневого цикория (в среднем за 2015-2019 годы) Table 4. Yield and commercial qualities of root chicory varieties (2015-2019)

\begin{tabular}{|c|c|c|c|c|}
\hline $\begin{array}{l}\text { № } \\
\text { nln }\end{array}$ & $\begin{array}{c}\text { Название } \\
\text { сортообразца }\end{array}$ & $\begin{array}{c}\text { Урожайность, } \\
\text { т/га }\end{array}$ & $\underset{\%}{\text { Товарность, }}$ & $\begin{array}{c}\text { «Цветуха», } \\
\%\end{array}$ \\
\hline 1 & Sleszka & 20,0 & 90,2 & 12,1 \\
\hline 2 & Spicak & 13,4 & 77,3 & 0,7 \\
\hline 3 & BilogorkaOS-3 & 21,3 & 82,1 & 1,3 \\
\hline 4 & BilogorkaOS-2 & 22,1 & 80,4 & 1,8 \\
\hline 5 & Подлуга Куявска & 18,8 & 79,2 & 2,0 \\
\hline 6 & Поляновицка & 19,3 & 87,3 & 0,3 \\
\hline 7 & Berguce & 18,5 & 73,4 & 7,1 \\
\hline 8 & TidWog & 16,3 & 81,5 & 11,9 \\
\hline 9 & Cassel & 18,9 & 77,6 & 17,3 \\
\hline 10 & Orchies & 18,9 & 73,4 & 11,3 \\
\hline 11 & AlbinoRVP & 16,8 & 83,2 & 1,8 \\
\hline 12 & Novipa & 15,7 & 81,9 & 2,3 \\
\hline 13 & Rexor & 18,7 & 78,3 & 7,1 \\
\hline 14 & Luxor & 17,1 & 80,4 & 9,2 \\
\hline 15 & Wixor & 18,4 & 88,9 & 8,4 \\
\hline 16 & LardRooted & 18,7 & 73,4 & 1,1 \\
\hline 17 & Wonfblan & 15,6 & 81,4 & 7,3 \\
\hline 18 & Харпачи & 22,1 & 89,5 & 7,8 \\
\hline 19 & Гаврилов-Ямский & 22,8 & 77,8 & 1,2 \\
\hline \multirow[t]{2}{*}{20} & Ярославский & 17,5 & 76,6 & 1,1 \\
\hline & $\mathrm{HCP}_{05}$ & 2,1 & 3,3 & 0,2 \\
\hline
\end{tabular}


По урожайности выделились сортообразцы ГавриловЯмский - 22,8 т/га, Харпачи и BilogorkaOS-2 - по 22,1 т/га, в то время, как у некоторых образцов этот показатель не превысил 16,0 т/га ( Spicak - 13,4 т/га, Wonfblan - 15,6 т/га, Novipa - 15,7 т/га). Следует отметить, что все эти сортообразцы относятся к группе с веретеновидным корнеплодом.

Товарность корнеплодов среди сортообразцов варьировала от 73,4\% до 90,2\%. Низкие показатели имели сортообразцы Berguce, Orchies, LardRooted (73,4\%). Все они относятся к группе с цилиндрической формой корнеплода. Высокой товарностью обладали образцы Sleszka $(90,2 \%)$ и Харпачи (89,5\%), которые относятся к группе с коническим коротким корнеплодом.

У цикория, как и у других корнеплодных растений, в результате воздействия некоторых факторов (сырая и холодная погода во время прорастания семян, возвратные заморозки во время вегетации культуры, избыточное минеральное питание и др.) цветоносные побеги могут появиться не во второй, а в первый год вегетации, так называемая «цветуха». В отдельные годы потери урожая от этого явления могут быть значительными. Разные сорта поразному реагируют на влияние неблагоприятных факторов внешней среды, следовательно, более или менее склонны к появлению «цветухи». Низкий процент зацветших в первый год вегетации растений наблюдался у сортов Поляновицка - 0,3\% и Spicak - 0,7\%, в то время как у сортообразцов Sleszka, TidWog, Orchies этот показатель превысил 10\%, а у сортообразца Cassel вовсе составил 17,3\%.

Главными критериями при отборе образцов для скрещивания следует считать форму корнеплода, урожайность, скороспелость, как наиболее значимые хозяйственно ценные признаки будущего сорта.

В числе селекционно ценных генотипов присутствуют сортообразцы, выделившиеся как по одному, так и по нескольким характеристикам (табл. 5).

Так, сортообразцы Харпачи и Sleszka имеют высокую урожайность, пригодную для механизированной уборки форму корнеплода, скороспелые, однако по результатам испытаний отличаются существенным наличием «цветушных» растений.

\section{Об авторах:}

Ольга Михайловна Вьютнова - кандидат с.-х. наук, старший научный сотрудник

Ирина Викторовна Смирнова - врио руководителя Елена Александровна Евсеева - научный сотрудник Татьяна Юрьевна Полянина - научный сотрудник Наталья Алексеевна Ратникова - научный сотрудник Ирина Александровна Новикова - научный сотрудник

\section{- Литература}

1. Боос Г.В., Казакова А.А., Буренин В.И. Современные аспекты изучения коллекции овощных и бахчевых культур. Труды по прикладной ботанике, генетике и селекции. 1983;(80):90-95

2. Прохоров И.А., Крючков А.В., Комиссаров В.А. Селекция и семеноводство овощных культур. М., Колос, 1981. С.59, 95-97, 108.

3. Жученко А.А. Экологическая генетика культурных растений. Кишинев, 3. Жученко А.А. Экологич
Штииниа, 1980. С.587.

4. Пивоваров В.Ф. Селекция и семеноводство овощных культур. Т.2. М., ВНИИСОК, 1999. С.58

5. Доспехов Б.А. Методика полевого опыта. М., Агропромиздат, 1985. C. $248-250$.

6. Белик В.Ф. Методика опытного дела в овощеводстве и бахчеводстве М., Агропромиздат, 1992. С.164-165.

7. Боос Г.В., Джохадзе Т.И., Артемьева А.М. и др. Методические указания по изучению и поддержанию мировой коллекции ВИР. Л., ВИР, 1988. С.118. 8. ОСТ 4671-78 «Делянки и схемы посева в селекции, сортоиспытании и первичном семеноводстве овощных культур. Параметры». М., 2003. 9. Руководству по апробации овощных культур и кормовых корнеплодов М., Колос. 1982.

10. РСТУ РСФСР 309 - 77, М., ГОСПЛАН РСФСР, 1982.
Сортообразцы BilogorkaOS-2, DilogorkaOS-3, ГавриовЯмский хорошо зарекомендовали себя по урожайности, но имеют длину вегетационного периода более 125 суток и длинные корнеплоды цилиндрической формы, которые не пригодны для механизированной уборки в условиях НЧЗ РФ.

блица 5. Селекционная ценность перспективных генотипов корневого цикория основным хозяйственно ценным признакам (в среднем за 2015-2019 годы)

Table 5. Breeding value of promising genotypes root chicory for the main economically valuable traits (2015-2019)
Название сортообразца

Харпачи

Sleszka

BilogorkaOS-2

BilogorkaOS-3

Гаврилов-Ямский

Rexor

Wixor

Luxor урожайность, форма корнеплода, скороспелость урожайность, форма корнеплода, скороспелость урожайность урожайность урожайность форма корнеплода, скороспелость форма корнеплода, скороспелость форма корнеплода, скороспелость
Характеристики

Сортообразцы голландской селекции Rexor, Wixor и Luxor имеют конические короткие корнеплоды, идеально подходящие для механизированной уборки, но уступают другим сортообразцам по урожайности и товарности.

Все выделившиеся по хозяйственно ценным признакам образцы следует использовать при скрещиваниях в качестве генисточников этих признаков.

\section{Выводы}

При создании исходного материала для селекции цикория корневого методом межсортовых скрещиваний одним из родителей следует выбирать местные внутризональные сорта, приспособленные к почвенно-климатическим условиям зоны цикоросеяния (Ярославский, Гаврилов-Ямский), а вторым - внезональные сорта, обладающие хозяйственно ценными качествами (короткий корнеплод, высокие урожайность и химико-технологические показатели, устойчивость к корневым гнилям) и являющиеся донорами этих признаков (Харпачи, Sleszka, BilogorkaOS-2, BilogorkaOS-3, Rexor, Wixor, Luxor).

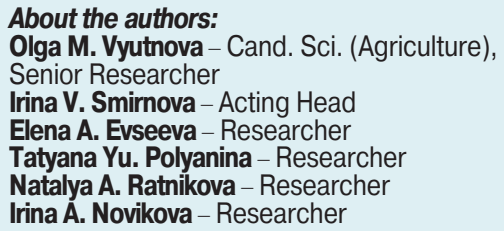

\section{- References}

1. Boos G.V., Kazakova A.A., Burenin V.I. Modern aspects of studying the collection of vegetable and melon crops. Works on applied botany, genetics and breeding. 1983; (80):90-95. (In Russ.)

2. Prokhorov I.A., Kryuchkov A.V., Komissarov V.A. Selection and seed production of vegetable crops. M., Kolos, 1981. Pp.59, 95-97, 108. (In Russ.)

3. Zhuchenko A.A. Ecological genetics of cultivated plants. Kishinev, Shtiintsa, 1980

3. Z877. (In Russ.)
4. Pivovarov V.F. Selection and seed production of vegetable crops. Vol. 2. M., 1999. P.58. (In Russ.)

5. Dospekhov B.A. Methodology of field experience. M., Agropromizdat, 1985 P.248-250. (In Russ.)

6 . Belik V.F. Methods of experimental work in vegetable and melon growing. $M$. Agropromizdat, 1992. P.164-165. (In Russ.)

7. Boos G.V., Dzhokhadze T.I., Artemeva A.M. Methodological guidelines for the study and maintenance of the world collection VIR. L., VIR, 1988. P.118. (In Russ.) 8. OST 4671-78 "Plots and seeding schemes in selection, variety testing and primary seed production of vegetable crops. Parameters". M., 2003. (In Russ.) 9 . "Guidelines for testing vegetable crops and fodder root crops", M., Kolos.

1982. (In RuSS.) 